RET : RMC

IV -3
U. S. DEPARTNENT OF CONMERCE NATIONAL BUREAU OF STANDARDS Washington 25, D.C.
Letter

Circular

IC864

\title{
June 10,1947
}

\begin{abstract}
Effect of Changes in Electrical and Photometric Units on Previously Assigned Values for Standard Lamps.
\end{abstract}

\section{INTRODUCTION}

In accordance with aecisions of the International Committee on Weights and Neasures, the National Bureau of Standards will introduce as of January I, 1948, revised values of the units of electricity and of light. While the definitions of the units and the methods of fixing their magnitudes will be quite different from those of the present practical systems, the changes in magnitude will be so small as to affect appreciably only measurements of the highest precision. In certificates and reports for standards and instruments issued by the Bureau during 1947 values will be given in both the old and the new units.

Since 1909, the unit of Iuminous intensity in the United States, as well as in France and Great Britain, has been the "international candle" and has boen maintoined by means of groups of carbon-filament vacuum lanips. The color temperature of these lamps is approximately $2100^{\circ} \mathrm{K}$. As types of lamps other than carbon were developed, secondary standards of the new types were derived without any specific international agrement. Nevertheless, the system thus established in this country covering the range from approximately 2100 to $2800^{\circ} \mathrm{K}$ has been known as the international systen, and values of candes and lumiens on this present system are conmonly designated as international candles and international lumens. Accordingly, there are now tungstenfilament vacuum lamp secondary standards of intensity and of flux at a color temperature of approximately $2400^{\circ} \mathrm{K}$ and tungsten-filament, gas-filled secondary standaras of intensity and of flux at a color temperature of approximately $2800^{\circ} \mathrm{K}$, as well as fluorescent and mercury-vapor lamp secondary standards.

It has long been realized that a reproducible primary standard should replace lamps as the basic standard of light. Measurements made in several national standardizing laboratories have shown that a black body at the temperature of solidification of platinum is a satisfactory primary standard.

\section{THE NEV PHOTONETRIC SYSTEN}

The establishment of the new photometric system has been based upon agreements reached at the biennial meeting of the International Committee on weights and Neasures in Paris, June 23 to 29, 1937. These are as follows: 
I. Beginning January I, 3940 the primary standard of light will be a black-body radiator operated at the temperature of solidification of platinum. The "candle", unit of intensity, is defined as one-sirtieth of the intensity of one square centimeter of such a radiator.

2(a). The values for photonetric magnitudes of sources of light differing in color from the primary standard shall be determined by a procedure consistent with the luminosity factors, formerly called "visibility factors", adopted by the International Comittee on Weights and Measures.

2(b). To assure uniformity among the national laboratories of the different countries in passing from the new prinary standard to secondary standards of the incandescent-filanent type operating at higher efficiency, the procedure adopted for the present is the use of blue filters which, interposed between the photometer and one of the standards to be compared, will make the colors in the two parts of the photometric field the same.

World events caused the postponement of the date for putting the new photometric scale into effect to January 1, 1948. On the same date, the "absolute" system of electrical units will supersede the present "international" system..

\section{EFFECTS OF THE CEANGES}

The changes in the magnitudes of the electrical units will be so small that only measurements of the highest precision will be affected appreciably. The electrical values assigned to photometric standaras will remain unchanged. The values of the candles or lumens assigned to existing photometric standard lamps in this country may be converted to the new system by using the factors listed below:

A. Carbon-filament, vacuum lamps (and other types operating at color temperatures of about $2100^{\circ} \mathrm{K}$ ). "New candles" obtained by multiplying present values by 1.019 .

B. Tungsten-filament, vacuum lamps (and other types operating at color temperatures in the range 2300 to $2500^{\circ} \mathrm{K}$ ). "New candles" ana "new .lumens" obtained by multiplying present values by 1.006 .

C. Tungsten-filament, gas-filled lamps (color temperature range 2600 to $3000^{\circ} \mathrm{K}$. " "New candles" obtained by multiplying present values by 0.997 . "New Iumens" obtained by multiplying present values by 0.994 . Intensity and lumen standards at $2800^{\circ} \mathrm{K}$ were established about 20. years apart. Improvements in technique and a redetermination of the ratio of luminous flux to lumirous intensity for these lamps resulted in the slightly different factors. 
D. Fluorescent and mercury-vapor lamps. No change in present ratings. Iamps of these types are less stable than filament lamps and the changes in the units are smaller than the experimental error in measuring these types of lamps. Furthermore, working standards of these types were established in accord with agreement $2(a)$. 
